\title{
Peculiarities of charge carriers transport in submicron Si-Ge whiskers
}

\author{
A.A.Druzhinin ${ }^{1,2}$, A.P.Dolgolenko $^{3}$, I.P.Ostrovskii $^{1,2}$, \\ Yu.N.Khoverko ${ }^{1,2}$, S.I.Nichkalo ${ }^{1,2}$, Iu.R.Kogut ${ }^{1}$ \\ ${ }^{1}$ Lviv Polytechnic National University, 1 Kotliarevskyi Str., \\ 79013 Lviv, Ukraine \\ ${ }^{2}$ International Laboratory of High Magnetic Fields and Low \\ Temperatures, 95 Gajowicka Str., Wroclaw 53-421, Poland \\ ${ }^{3}$ Institute for Nuclear Research, National Academy of Sciences of Ukraine, \\ 47 Prospect Nauky, 03680 Kyiv, Ukraine
}

\section{Received November 28, 2014}

\begin{abstract}
The paper presents an analysis of impact of charge carriers transport mechanisms on the thermoelectric properties of Si-Ge submicron whiskers. Based on the resistance temperature dependences the value of activation energy for conduction submicron designs was estimated and compared with the ones for micron-scale crystals. It is shown that the activation energy of ground state $\varepsilon_{1}$ of boron impurity for the Si-Ge whiskers with a diameter of $200 \mathrm{~nm}$ is $29.6 \mathrm{meV}$, which is typical for the bulk materials, whereas $\varepsilon_{2}$ was $3.2 \mathrm{meV}$. It is suggested that the unusual high value of $\varepsilon_{2}$ caused by inhomogeneous stress at the interface between the core and nanoporous shell of the submicron whisker due to their lattice mismatch. This effect can be used to create gauges with a thermoelectric principle of operation for cryogenic temperatures.
\end{abstract}

Keywords: Si-Ge submicron whiskers, create gauges, cryogenic temperatures.

Представлен анализ влияния механизмов переноса носителей заряда на термоэлектрические характеристики субмикронных нитевидных кристаллов (HK) Si-Ge. Ha основе построенных температурных зависимостей сопротивления оценено значение энергии активации проводимости для субмикронных образцов и проведено их сравнение с кристаллами микронного масштаба. Показано, что энергия активации проводимости $\varepsilon_{1}$ основного состояния примеси бора для образцов $\mathrm{HK} \mathrm{Si}-\mathrm{Ge}$ с диаметром 200 нм равна 29.6 мэВ, что характерно для объемных материалов, тогда как $\varepsilon_{2}$ составила 3.2 мэВ. Сделано предположение, что нетипично высокое значение $\varepsilon_{2}$ вызвано неоднородным напряжением на границе между ядром и нанопористой оболочкой субмикронного НК вследствие несоизмеримости их параметров кристаллической решетки. Данный эффект можно использовать для создания сенсоров с термоэлектрическим принципом действия для криогенных температур.

Особливості перенесення носіїв заряду в субмікронних ниткоподібних кристалах Si-Ge. А.О.Дружинін, О.П.Долголенко, І.П.Островський, Ю.М.Ховерко, С.І.Нічкало, Ю.P.Когут.

Представлено аналіз впливу механізмів перенесення носіїв заряду на термоелектричні характеристики субмікронних ниткоподібних кристалів (HК) Si-Ge. На основі побудованих температурних залежностей опору оцінено значення енергії активації провідності для субмікронних зразків та проведено їх порівняння з кристалами мікронного масштабу. Показано, що енергія активації провідності $\varepsilon_{1}$ основного стану домішки бору 
для зразків HK Si-Ge з діаметром 200 нм дорівнює 29.6 меВ, що характерно для об’ємних матеріалів, натомість $\varepsilon_{2}$ становила 3.2 меВ. Зроблено припущення, що нетипово високе значення $\varepsilon_{2}$ спричинено неоднорідним напруженням на межі між ядром $\mathrm{i}$ нанопористою оболонкою субмікронного НК внаслідок несумірності їх параметрів кристалічної гратки. Даний ефект можна використати для створення сенсорів з термоелектричним принципом дії для кріогенних температур.

\section{Introduction}

Thanks to their unique physical and mechanical properties, the structurally perfect $\mathrm{Si}$ and $\mathrm{Si}-\mathrm{Ge}$ whiskers have long proven to be a good material for making gauges of physical parameters (temperature, pressure, strain, magnetic field, etc.) [1]. However, with decreasing lateral dimensions of whiskers to submicron scale the quantum size effects are observed, which change the energy spectrum of charge carriers, phonons and their interaction, and can be as useful as undesirable in terms of functionality. Changes also occur under the influence of external factors: strain, magnetic field, low temperatures and so on. Furthermore, in terms of thermometric properties, the authors of $[2,3]$ conducted a deep study of charge carrier transport mechanisms in complex thermoelectric materials, including bulk Si-Ge, and analyzed its effect on thermoelectric properties of the material, including thermopower and thermal conductivity. To use Si-Ge solid solution whiskers as sensitive elements of temperature sensors with thermoelectric principle of action, it is important to study and control the phonon drag effect, which makes a significant contribution to the thermopower [4-8]. In particular, in [8] it was shown that phonon drag effect strongly depends on the sign and the value of uniaxial strain applied to whisker. However, in submicron whiskers it should be taken into account the harmonic phonon scattering (at grain boundaries and crystal lattice defects), and scattering caused by anharmonic interactions between phonons, for example, due to non-uniform three-dimensional stress. The both types of scattering lead to changes in the interaction of electron and phonon subsystems of the crystal and the processes of heat transfer and charge carriers transport in it [2]. Submicron $\mathrm{Si}$ and $\mathrm{Si}-\mathrm{Ge}$ whiskers represent a so-called "core-shell" structure consisting of crystalline core and nanoporous shell, the lattice parameter and elemental composition of which differs from the crystalline core $[9,10]$. And as it was shown in $[11,12]$ the presence of the nanoporous shell affects the magnetic susceptibility and magnetoresistance of $\mathrm{Si}-\mathrm{Ge}$ whiskers.

The aim of this paper was to analyze the effect of charge carriers transport mechanisms on thermoelectric properties of submicron Si-Ge whiskers what could be used to predict the output parameters of sensors of thermal quantities.

\section{Experimental}

The submicron Si-Ge whiskers were grown by chemical vapor deposition (CVD) in closed bromide system and in situ doped with boron to concentrations corresponding the room temperature resistivity of $\rho_{300 \mathrm{~K}}=$ $0.01 \Omega \cdot \mathrm{cm}$. Examined by electron microprobe analysis the content of $\mathrm{Ge}$ in whiskers amounts to 3 at. \%.

Scanning electron microscopy (SEM, JEOL JSM-6490LV) investigation of the whiskers revealed the growth of randomly distributed Si-Ge submicron wires with an average thickness of $200 \mathrm{~nm}$ (Fig. 1). HRTEM studies of the Si-Ge submicron whiskers and nanowires have shown the formation of natural heterostructure in them consisting of single-crystalline core and nanoporous shell, i.e. "core-shell" structure (Fig. 2).

The ohmic electrical contacts to $200 \mathrm{~nm}$ thick Si-Ge whiskers were made by previously developed method with using a composite on the basis of In-Ga featuring the high electrical conductivity in temperature range of $(4.2-300) \mathrm{K}$ [13].

The low temperature measurements of electrical conductivity and thermopower of the Si-Ge whiskers have been carried out

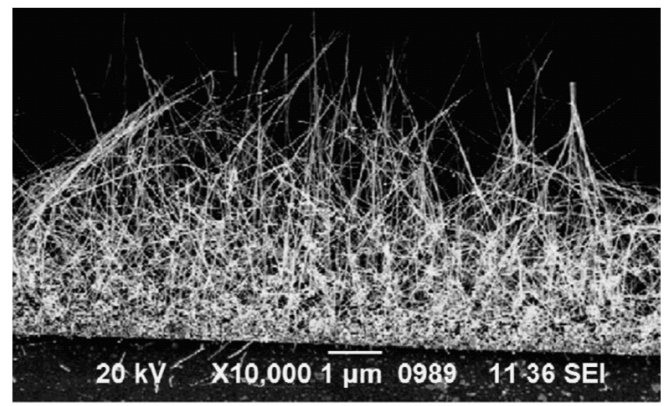

Fig. 1. SEM image of CVD grown Si-Ge whiskers. 


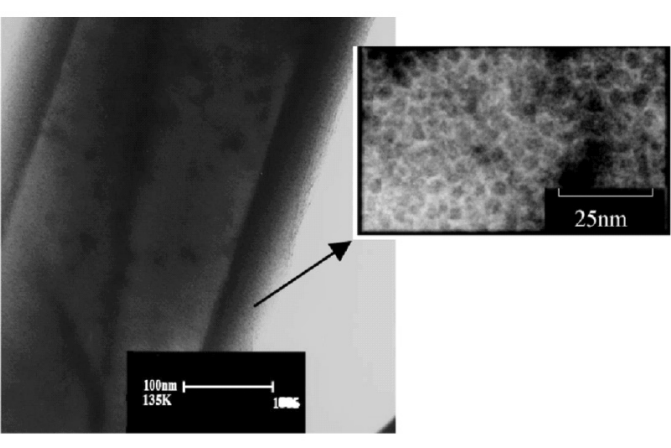

Fig. 2. SEM image of single Si-Ge whisker $(d=200 \mathrm{~nm})$.

using method described in [7, 14]. The stabilized electrical current via the crystals was generated by a Keithley 224 in a range of 1 to $100 \mu \mathrm{A}$ depending on the crystal's resistance. The output voltage signal was measured by Keithley 199 and Keithley 2000 digital multimeters.

\section{Results and discussion}

An exemplary temperature dependence of submicron Si-Ge whiskers' resistance in the range of $4.2-300 \mathrm{~K}$ is depicted in Fig. 3. As it could be seen the resistance of the whiskers depends almost linearly on temperature in (4.2-77) $\mathrm{K}$ range and sharply decreases inferring the semiconductor behavior of the crystal. At temperatures of (100-120) K the onset of metallic-like conductivity has been observed, which is consistent with the heavily doped semiconductors' behavior.

As it is well known in general the conductivity of a semiconductor can be described as a sum $[15,16]$ :

$$
\sigma=\sum_{i=1}^{3} \sigma_{i} \cdot \exp \left(\varepsilon_{i} / k T\right),
$$

where $\sigma_{i}$ - the temperature independent coefficients, $\varepsilon_{i}$ - denominate the activation energies inherent for different conductivity

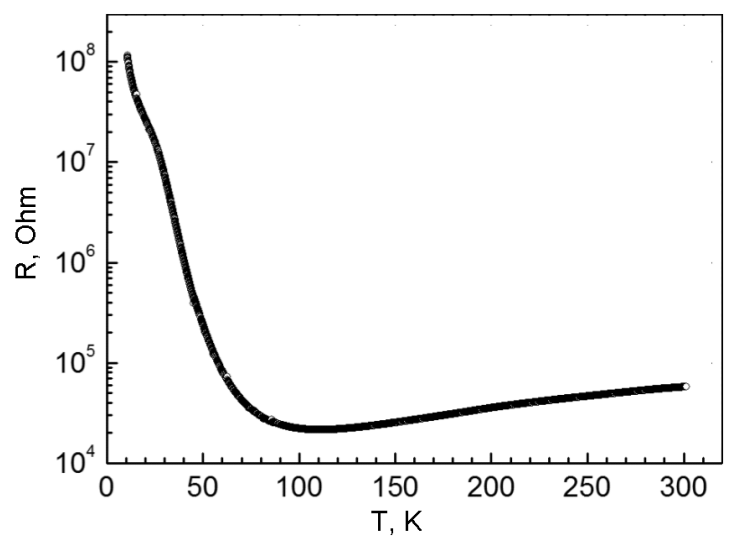

Fig. 3. Typical temperature dependence of resistance of Si-Ge $\left(d=200 \mathrm{~nm}, \rho_{300 \mathrm{~K}}=\right.$ $0.01 \Omega \cdot \mathrm{cm})$.

mechanisms at various temperatures. A kink of $R(T)$ curve of the submicron Si-Ge whiskers at $T \approx 25 \mathrm{~K}$ implies the activation of $\sigma_{2}$ conductance via the delocalized states of impurity band in non-compensated semiconductor heavily doped to the impurity concentrations in the immediate vicinity to metal-insulator transition (MIT).

In order to analyze the charge carriers transport mechanism in the Si-Ge whiskers we have calculated the corresponding activation energies of conductivity in the boron doped Si-Ge submicron whiskers and compared them to the micron scale ones (see Table).

The calculation results showed that the activation energy $\varepsilon_{1}$ of the boron impurity ground state in the heavily doped $200 \mathrm{~nm}$ thick Si-Ge whiskers is less than that of typical values for the bulk-like $20 \mu \mathrm{m}$ thick Si-Ge samples $(49 \mathrm{meV})$ and amounts to $29.6 \mathrm{meV}$. At the same time, the value of activation energy $\varepsilon_{2}$ amounts to $3.2 \mathrm{meV}$ what is not typical value for the whiskers with this doping level.

The revealed changes in activation energy of $200 \mathrm{~nm} \mathrm{Si-Ge} \mathrm{whiskers} \mathrm{cannot} \mathrm{be}$

Table. Activation energies $\varepsilon_{i}$ for Si-Ge whiskers with various resistivities

\begin{tabular}{||c|c|c|c||}
\hline Diameter of whisker & $\rho_{300 \mathrm{~K}}, \mathrm{Ohm} \cdot \mathrm{cm}$ & $\varepsilon_{1}, \mathrm{meV}$ & $\varepsilon_{2}, \mathrm{meV}$ \\
\hline $200 \mathrm{~nm}$ & 0.01 & 29.6 & 3.2 \\
$20 \mu \mathrm{m}$ & 0.012 & - & 1.35 \\
$20 \mu \mathrm{m}$ & 0.018 & - & 1.6 \\
$20 \mu \mathrm{m}$ & 0.02 & 49.0 & 1.6 \\
$20 \mu \mathrm{m}$ & 0.025 & - & 3.6 \\
\hline
\end{tabular}


explained by the quantum size effects, since ascertained impurity activation energy $\left(\varepsilon_{1}=\right.$ $29.6 \mathrm{meV}$ ) corresponds to the value of the bulk samples. Instead, the effect can be explained in terms of the influence of stress accumulated in the submicron whiskers. The latter consistent with hypotheses which have been put forward in [17], here the authors have shown that in boron doped silicon with impurity concentration in the vicinity to MIT the applied strain leads to a so called effect of "deformational charge carriers freezing". In other words, the strain is a significant factor in the conductivity region $\sigma_{2}$, which leads to its reduction what naturally explains the increasing of $\varepsilon_{2}$ value. For the micron scale whiskers the increasing of $\varepsilon_{2}$ value usually is explained by tensile nature of the stress, so we assume that the uncharacteristically high value of $\varepsilon_{2}$ in the submicron Si-Ge whiskers is related to the effects arising at the core-shell interface of the crystal. In particular, due to the lattice mismatch between the core and nanoporous shell the elastic strain is accumulated at the interface where the core undergoes partial tensile stress, which subsequently contributes to electrical conductivity of the submicron Si-Ge whiskers.

The further study of submicron Si-Ge whiskers electrophysical properties comprised the investigation and analysis of thermoelectromotive force in them. The analysis of size-dependent effects on thermopower of the whiskers considering the phonon scattering and phonon drag of charge carriers were grounded on the theoretical analysis based on calculations of collision integrals value according to the procedure described in [18].

The differential thermal e.m.f. $(\alpha)$ of semiconductor with one type of charge carriers is defined as:

$$
\alpha= \pm \frac{k}{e}\left(\frac{Q^{*}}{k T}-\eta\right), \quad \eta=\frac{F}{k T},
$$

where the sign coincides with the sign of charge carrier, $\eta-$ a reduced Fermi energy, $k$ - stands for Boltzmann constant, $T$ - an absolute temperature and $Q^{*}$ is a transfer energy:

$$
Q^{*}=k T(r+2) \frac{F_{r+1}(\eta)}{F_{r}(\eta)} .
$$

The value $r$ is determined by a charge carrier scattering mechanism. At temperatures higher than Debye temperature $\left(\theta_{D}\right) r=1$. Then:

$$
\alpha=\mp \frac{k}{e}\left[(r+2) \frac{F_{r+1}(\eta)}{F_{r}(\eta)}-\eta\right],
$$

where $F_{r+1}(\eta)$ and $F_{r}(\eta)$ are the Fermi integrals of $r$ degree. In case of $\eta>-1$ the Fermi integrals are equal to:

$$
\begin{gathered}
F_{1 / 2}=\frac{2}{3}\left(\eta^{3 / 2}+\frac{\pi^{2}}{8} \eta^{-1 / 2}\right) \frac{2}{\sqrt{\pi}} \\
F_{1}=\frac{1}{2}\left(\eta^{2}+\frac{\pi^{2}}{3}\right) \\
F_{2}=\frac{1}{3}\left(\eta^{3}+\pi^{2} \eta\right) \frac{1}{2}
\end{gathered}
$$

But within the interval $-1>\eta>-\infty$ for integral $F_{1 / 2}$ it is correct to approximate the next:

$$
F_{1} \sqrt{2}=\left(\sqrt{\frac{\pi}{4}}\right) \cdot \exp (\eta)
$$

If scattering is determined by only one mechanism, then:

$$
\alpha=\frac{k}{e} \cdot\left[\frac{5}{2}+p+\ln \frac{N_{V}}{n}\right],
$$

where $p$ is the exponent of the energy dependence for the carrier relaxation time, $n$ - charge carriers concentration of the sample, $N_{V}$ - denominates the density of states in valence band. Then, it is possible to describe the dependence of $F_{1 / 2}$ on absolute thermopower $\alpha$ and knowing $F_{1 / 2}$ to obtain the charge carriers concentrations:

$$
n=\frac{2}{\sqrt{\pi}} N_{V} \cdot F 1_{2} .
$$

According to the electroneutrality condition for extrinsic semiconductor, the concentration of holes dependent on temperature is described as:

$$
\begin{aligned}
n(T) & =\left[\left(\beta \cdot N_{V}(T) \exp \left(\frac{E_{a}}{k T}\right)+N_{d}\right)^{2} \cdot \frac{1}{4}+\right. \\
& \left.+\beta \cdot N_{V}(T) \cdot N_{a} \cdot \exp \left(\frac{E_{a}}{k T}\right)\right]^{1 / 2}- \\
& -\frac{1}{2}\left(\beta \cdot N_{V}(T) \cdot \exp \left(\frac{E_{a}}{k T}\right)+N_{d}\right)
\end{aligned}
$$

Functional materials, 22, 1, 2015 


$$
\begin{gathered}
N_{V}(T)= \\
=2.5 \cdot 10^{19} \cdot m_{p}^{3 / 2} \cdot\left(\frac{T}{300}\right)^{3 / 2} \cdot \frac{1}{\left(1+5 \cdot \exp \left(-\frac{0.01}{k T}\right)\right)},
\end{gathered}
$$

where $\beta$ is the degree of degeneracy of boron acceptor level $(1 / 2)$.

Within the region of mixed scattering at high doping level the carriers scattering mechanism is described with the value $r=1$. In case of scattering on acoustic phonons $r$ $=-1 / 2$, and on ionized impurities $r=3 / 2$. Interaction of carriers with phonons is determined by the collision integral: $S_{e p}=\mathrm{S}_{e p} e$ $+S_{e p} p$. The integral $S_{e p}{ }^{e}$ describes collision with equilibrium phonons, whereas $S_{e p}{ }^{p}$ considers the nonequilibrium phonons, and it is critical for drag of carriers by phonons. The holes scattering by phonons turns thermopower to $\alpha \sim T^{-2.3}$. At low temperatures, $\alpha$ is proportional to the specific heat capacity per volume unit. Since the specific heat capacity is proportional to $T^{3}$ at $T<<\theta_{D}$, the thermopower $\alpha(T)$ is also proportional to $T^{3}$. Thus, the collision integral can be defined as:

$$
S_{e p}=\frac{l}{d}+g \cdot T^{3}+h \cdot T^{-2.32} .
$$

The contribution of phonon drag effect into thermal e.m.f. should contain the parameter $l / d$, where $d$ is the crystal lateral dimension and $l$ is carriers mean free path. At very low temperatures phonon scattering on crystal boundaries limits the drag effect. On the other hand, at the subsurface regions of crystal there are gradients of nonequilibrium carrier concentrations that collapse to the bulk ones at the distances of the order of diffusion length, which from the viewpoint of phonon drag effect should be treated as concentration decompensation. The phonon-phonon scattering also decreases the drag effect. That's why the phonon drag effect is negligibly small at the room temperatures and is weakly manifested at thermopower measuring, whereas at the low temperatures the thermopower reduces with decreasing of the crystal's diameter.

Using the equation of electroneutrality (11) the impact of phonon drag effect and phonon scattering in thermoelectric power of bulk $p-\mathrm{Si}-\mathrm{Ge}$ compared with $p-\mathrm{Si}-\mathrm{Ge}$ submicron whiskers was calculated.

The collision integral was calculated by selecting the coefficients in expression (12) in such manner that the determined values

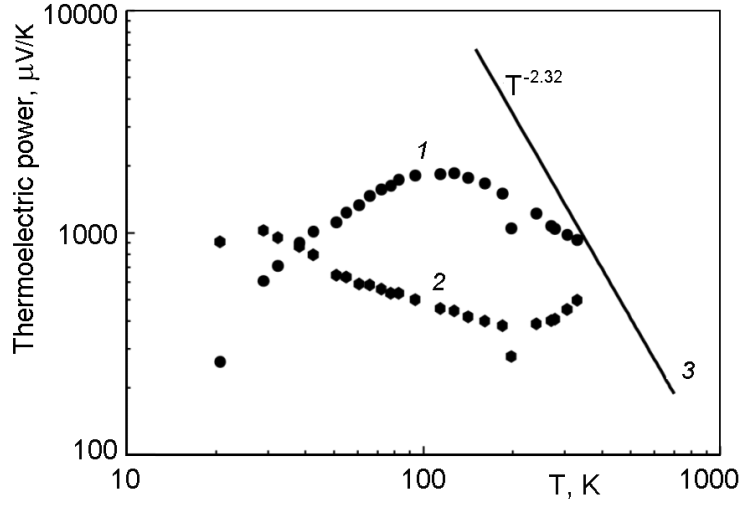

Fig. 4. Temperature dependences of thermoelectric power of bulk $p-\mathrm{Si}-\mathrm{Ge}$ taken from [15] (1) and with account of phonon drag effect and phonon scattering (2); $\alpha \sim T^{-2.32}$ (3).

of the Fermi integral of degree $1 / 2$ from its functional dependence on thermopower $\left(F_{1 / 2}(\alpha)\right)$ allows to reliably determine the holes concentration. The values of coefficients: $l / d=0.17 ; g=1 \cdot 10^{-8} ; h=3.7 \cdot 10^{3}$ and the collision integral are dimensionless. The impact of collision integral on the experimentally determined thermopower is presented in Fig. 4.

After being certified in reliability of the function $F_{1 / 2}(\alpha)$, and after determining the coefficients in collision integral $(l / d=0.21$; $g=3.5 \cdot 10^{-8} ; \quad h=6.5 \cdot 10^{3}$, using equation (11) the holes concentration of $p-\mathrm{Si}-\mathrm{Ge}$ wires was calculated and the influence of collision integral on experimentally measured thermopower is shown in Fig. 5. The calculated holes concentration amounted to $5 \cdot 10^{18} \mathrm{~cm}^{-3}$. As it is obvious, the coefficients of collision integral for the Si-Ge submicron wires, in comparison with the bulk ones, have increased. The increase of $g$ for the Si-Ge whiskers testifies that phonons transfer high energy to charge carriers, and thus the phonon drag effect is strengthened, while the increase of $h$ coefficient indicates the decrease of the carriers scattering by phonons. Probably the increased phonon drag effect in the submicron $p$-Si-Ge whiskers is due to the core-shell interface tensile stress accumulated. As it has been shown in [7, 14] tensile strain significantly affects the thermopower, in particular, the phonon drag effect is increased and the maximum of $\alpha(T)$ curve shifts towards higher temperatures. The latter is confirmed in our experiments by comparison of the temperature dependence of ther- 


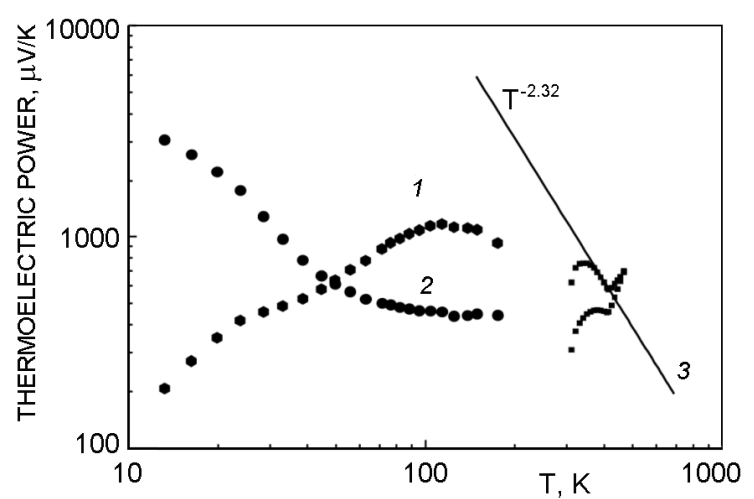

Fig. 5. Temperature dependences of thermoelectric power of $p-\mathrm{Si}-\mathrm{Ge}$ whisker $(d=$ $200 \mathrm{~nm}): 1$ - experiment; 2 - with account of phonon drag effect and phonon scattering; $3-\alpha \sim T^{-2.32}$.

mopower of the submicron $p-\mathrm{Si}-\mathrm{Ge}$ whiskers with the previously reported results for the micron size Si-Ge whiskers studied previously [7] (Fig. 6).

The results obtained can be used to improve the thermopower of $p$-Si-Ge whiskers via controlling the size of the submicron whisker's core and shell in growth process. From the practical standpoint based on this effect the sensor of temperature and temperature difference qcould be developed, where the thermoresistive branch is used to measure temperature and the thermoelectric branch - the temperature difference. From the fundamental point of view the described effect is consistent with current physical notions about improving the thermoelectric figure of merit in the low-dimensional materials.

\section{Conclusions}

When developing gauges of physical parameters based on whiskers, especially for cryogenic temperatures, it is necessary to consider the influence of various factors on their electrical properties that determine the output parameters and the working range of the devices. In particular, studies have shown that the structure peculiarities of submicron Si-Ge whiskers significantly affect the mechanisms of charge carriers transport in them. Thus, the determined value of conductivity activation energy $\varepsilon_{2}$ in the Si-Ge whiskers with an average diameter of $200 \mathrm{~nm}$ is uncharacteristically high in comparison with micron scale whiskers and identical doping level. On the other hand, theoretical calculations indicate on

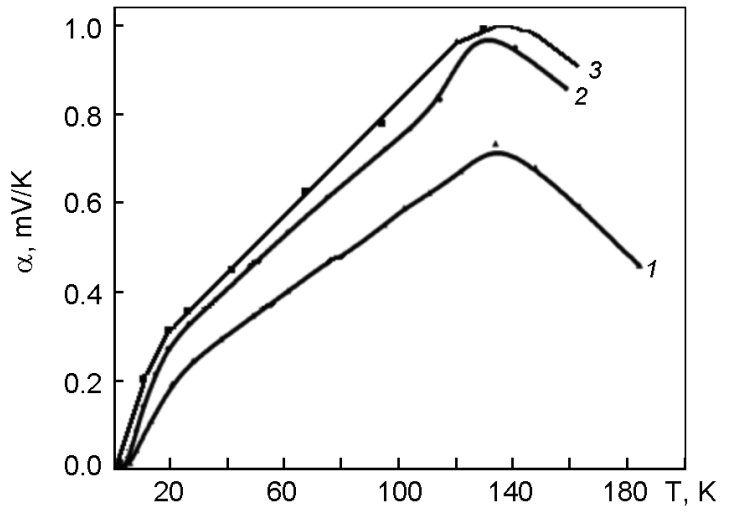

Fig. 6. Temperature dependences of thermoelectric power of Si-Ge single whisker: 1 - free $p$-Si-Ge whisker $\left(d=20 \mu \mathrm{m}, \quad \rho_{300 \mathrm{~K}}=\right.$ $0.02 \Omega \cdot \mathrm{cm})$, taken from [7]; $2-p-\mathrm{Si}-\mathrm{Ge}$ whisker on quartz substrate $(d=20 \mu \mathrm{m}$, $\left.\rho_{300 \mathrm{~K}}=0.02 \Omega \cdot \mathrm{cm}\right)$, taken from [7]; $3-p-\mathrm{Si}-\mathrm{Ge}$ whisker $\left(d=200 \mathrm{~nm}, \rho_{300 \mathrm{~K}}=0.01 \Omega \cdot \mathrm{cm}\right)$.

the decreasing of phonon scattering by charge carriers and increasing of phonon drag effect in these crystals. Both observations denote the suppression of charge carriers transport in the submicron Si-Ge whiskers, what explains the uncharacteristically high values of conductivity activation energy $\varepsilon_{2}$. Probable reason for this is the presence of stress at the core-shell interface of such "core-shell" structure which is inherent to the submicron whiskers. However, to confirm or deny assumptions it is necessary to carry out several studies of whiskers with different cross size and doping concentrations. Low-temperature Hall measurement and studies of thermal conductivity will allow better explain the scattering mechanisms in the submicron whiskers and assess their possible applications in gauges of physical parameters.

\section{References}

1. A.O.Druzhinin, Silicon, Germanium and Their Solid Solutions in Sensor Electronics, Lviv Polytechnic Publishing House, Lviv (2010) [in Ukrainian].

2. G.J.Snyder, E.S.Toberer, Nat.Mater., 7, 105 (2008).

3. L.Dubois, in: Proc. of $18^{\text {th }}$ Int. Conf. on Thermoel., Baltimore, USA (1999), p.1.

4. W.Lu, C.M.Lieber, J.Phys. D:Appl.Phys., 39, R387 (2006).

5. V.G.Dubrovskii, G.E.Cirlin, V.M.Ustinov, Semiconductors, 43, 1585 (2009).

6. N.Wang, Y.Cai, R.Q.Zhang, Mater. Sci. and Engin., R 60, 1 (2008). 
7. A.O.Druzhinin, I.P.Ostrovsky, Yu.R.Kohut, J. Thermoelectricity, 3, 86 (2007).

8. A.Druzhinin, I.Ostrovskii, N.Liakh, Mater. Sci.Semic. Proc., 8, 193 (2005).

9. A.I.Klimovskaya, I.V.Prokopenko, I.P.Osrovskii, J.Phys:Condens.Matter., 13, 5923 (2001).

10. A.I.Klimovskaya, I.V.Prokopenko, S.V.Svechnikov et al., Mater. Sci and Engin.C, 19, 205 (2002).

11. A.O.Druzhinin, I.P.Ostrovskii, Yu.M.Khoverko et al., J.Nanosc. and Nanotech., 12, 8690 (2012).

12. A.O.Druzhinin, I.P.Ostrovskii, Yu.R.Kogut et al., Functional Materials, 4, 480 (2007).
13. A.O.Druzhinin, Yu.M.Khoverko, I.P.Ostrovskii et al., Phys. and Chem. Sol.State, 13, 269 (2012).

14. A.Druzhinin, I.Ostrovskii, Iu.Kogut, Mater. Sci.Semic. Proc., 9, 853 (2006).

15. F.J.Morin, J.P.Maita, Phys.Rev., 96, 28 (1954).

16. N.F.Mott, Metal-Insulator Transitions, Taylor and Francis LTD, London (1974).

17. P.I.Baranskii, I.S.Buda, A.G.Samoilovich, Semiconductors, 8, 2159 (1974).

18. A.P.Dolgolenko, A.A.Druzhinin, A.Ya.Karpenko et al., Semicond.Phys.\& Quant. El., 14, 456 (2011). 